\title{
Climatic constraints on maximum levels of human metabolic activity and their relation to human evolution and global change
}

\author{
Axel Kleidon
}

Received: 17 January 2006 / Accepted: 4 December 2008 / Published online: 5 March 2009

(C) The Author(s) 2009. This article is published with open access at Springerlink.com

\begin{abstract}
No matter what humans do, their levels of metabolic activity are linked to the climatic conditions of the land surface. On the one hand, the productivity of the terrestrial biosphere provides the source of chemical free energy to drive human metabolic activity. On the other hand, human metabolic activity results in the generation of heat within the body. The release of that heat to the surrounding environment is potentially constrained by the climatic conditions at the land surface. Both of these factors are intimately linked to climate: Climatic constraints act upon the productivity of the terrestrial biosphere and thereby the source of free energy, and the climatic conditions near the surface constrain the loss of heat from the human body to its surrounding environment. These two constraints are associated with a fundamental trade-off, which should result in a distinct maximum in possible levels of human metabolic activity for certain climatic conditions. For present-day conditions, tropical regions are highly productive and provide a high supply rate of free energy. But the tropics are also generally warm and humid, resulting in a low ability to loose heat, especially during daylight. Contrary, polar regions are much less productive, but allow for much higher levels of heat loss to the environment. This trade-off should therefore result in an optimum latitude (and altitude) at which the climatic environment allows humans to be metabolically most active and perform maximum levels of physical work. Both of these constraints are affected by the concentration of atmospheric carbon dioxide $\mathrm{pCO}_{2}$, but in contrary ways, so that I further hypothesize that an optimum concentration of $\mathrm{pCO}_{2}$ exists and that the optimum latitude shifts with $\mathrm{pCO}_{2}$. I evaluate these three hypotheses with model simulations of an Earth system model of intermediate complexity which includes expressions for the two constraints on maximum possible levels of human metabolic activity. This model is
\end{abstract}

\footnotetext{
A. Kleidon $(\bowtie)$

Biospheric Theory and Modelling Group, Max-Planck-Institut für Biogeochemie,

Postfach 1001 64, 07701 Jena, Germany

e-mail: akleidon@bgc-jena.mpg.de
} 
used to perform model simulations for the present-day and sensitivity experiments to different levels of $\mathrm{pCO}_{2}$. The model simulations support the three hypotheses and quantify the conditions under which these apply. Although the quantification of these constraints on human metabolic activity is grossly simplified in the approach taken here, the predictions following from this approach are consistent with the geographic locations of where higher civilizations first emerged. Applied to past climatic changes, this perspective can explain why major evolutionary events in human evolutionary history took place at times of global cooling. I conclude that the quantification of these constraints on human metabolic activity is a meaningful and quantitative measure of the "human habitability" of the Earth's climate. When anthropogenic climate change is viewed from this perspective, an important implication is that global warming is likely to lead to environmental conditions less suitable for human metabolic activity in their natural environment (and for large mammals in general) due to a lower ability to loose heat.

\section{Introduction}

The question of how climate and other environmental factors have shaped human evolutionary history have long been subject to scientific inquiry (Ritter 1852; Huntington 1915; Lamb 1982; Vrba et al. 1995). The environment, most importantly through factors such as temperature and the availability of food and water, shapes where humans can live, and how much effort they need to allocate to the acquisition of resources to meet their basic needs. It is quite obvious that climate, and related environmental factors, must play a critically important role in shaping the presence and development of humans throughout history.

In its strongest form, climate-related explanations of human evolution amount in the controversial notion of "environmental determinism" (Huntington 1915). Environmental determinism states that human attributes, such as "laziness", can be determined from climate. While the strongest form of environmental determinism can easily be rejected - after all, humans are not just robots acting all alike - this does not lessen the fundamental role of climate in constraining what humans can - and cannot - do in a given natural environment. The lack of water prevents large number of humans to live in a desert environment (unless it is compensated by some form of technology - for simplicity, such factors are excluded here). Likewise, the lack of available food resources in the high arctic prevents large civilizations to form as well. These two examples emphasize the role of environmental constraints, not in the sense that they determine human behavior, but in that they constrain possible levels of human metabolic activity and thereby human behavior.

Along these lines, Diamond (1997) has given an account of how simple geographic constraints can explain some of the main features of the course of human history since the emergence of agriculture. One of his main assertions is that the course of human history was strongly preconditioned by what is available (i.e. non-constraining in a broader sense) in a given region - in terms of suitable plants and animals for agriculture and food production and in terms of the ability of the gained knowledge to spread within similar climatic regions on continents. His analysis emphasizes the highly favorable conditions in the fertile crescent in Western Asia, where the 
majority of today's agricultural grains and domesticated animals originated, and a geographic location where humans can easily migrate in the East-West direction and remain in a similar climatic environment.

When we view human evolutionary history in a broader context, we need to recognize that the climatic environment has changed considerably (Crowley and North 1991). These climatic changes affect the conditions - and constraints - for primates and humans to evolve in Vrba et al. (1995). Two relevant characteristics, global mean temperature, and the concentration of atmospheric carbon dioxide, capture the general trends of climatic changes, and play dominant roles in humanrelated evolution:

Global mean temperature: Over the last 50 million years, climate shifted to subsequently cooler conditions, as for instance recorded in deep-sea oxygen isotopes (Zachos et al. 2001) and $\mathrm{Mg} / \mathrm{Ca}$ ratios (Lear et al. 2000) that translate into a cooling of up to $12^{\circ} \mathrm{C}$. This global cooling trend is also mirrored in the onset of Antarctic glaciation around 35 million years ago, and the onset of Northern Hemisphere ice sheet growth around 2.5 million years ago. These global changes were mirrored by accompanying changes over land. A globally cooler climate is generally drier, changing the growing conditions of the terrestrial biota. The drier conditions are reflected in the shift to extended Savanna and desert environments in Africa, and a transition to more drought-tolerant C4 vegetation (Cerling et al. 1997). The onset of Northern Hemisphere glaciation roughly coincides with the the emergence and evolution of Homo habilis and Homo erectus, which are characterized by a greater brain biomass in relation to body weight compared to its ancestors (Vrba 1995). Schwartzman and Middendorf (2000) suggested that this cooling trend over the last 50 million years allowed for the emergence of mammals with "big brains" ("encephalization", i.e. evolution towards a greater ratio of brain to body weight), particularly humans in the last 2 million years. The maintenance of big brains consumes a substantial fraction of the basal metabolic rate (Allman 1999). In a cooler climate, it is easier to loose the heat generated by metabolic activity to the environment. To quantitatively describe environmental constraints on the amount of possible heat loss, it is also important to account for the large latitudinal variation in surface temperature found between the tropics and poles.

Atmospheric carbon dioxide: Over the same 50 million years, $p \mathrm{CO}_{2}$ varied greatly, from about $3000 \mathrm{ppm}$ in the early Eocene (Pearson and Palmer 2000) to glacialinterglacial fluctuations between 180ppm and $280 \mathrm{ppm}$ over the last 420,000 years (Petit et al. 1999). The fluctuations in $\mathrm{pCO}_{2}$ are important as they affect global mean temperature. Other greenhouse gases, such as methane, have also changed considerably. For matters of simplicity, I will focus here only on changes in $\mathrm{pCO}_{2}$ and investigate changes in $T_{s}$ only with respect to differences in $\mathrm{pCO}_{2}$. Furthermore, $p \mathrm{CO}_{2}$ directly affects plant productivity, with higher levels of $p \mathrm{CO}_{2}$ leading to higher rates of productivity if other factors remain unaffected (the " $\mathrm{CO}_{2}$ fertilization" effect, e.g. Larcher 1995, but also see Long et al. 2006 for possible overestimation of this effect). Plant productivity in turn affects leaf growth and seed production and thereby the supply rate of chemical free energy to the terrestrial fauna, including humans. In this context Sage (1995) hypothesized that the increased levels of $p \mathrm{CO}_{2}$ at the termination of the last ice age was a necessary requirement for the 
development of agriculture in that it led to higher allocation to seed production in grasses, and thereby made agriculture feasible. Diamond (1997) then argued that the emergence of agriculture builds the foundation for the subsequent emergence of higher civilizations.

The goal of this paper is to combine and quantify the extent to which these two environmental effects could affect maximum levels of human metabolic activity. It does not specify how climate determines what individual humans do, but rather quantifies the extent to which climatic factors limit possible levels of metabolic activity of all humans within a given region. This distinction is critical - in this paper, human metabolic activity will only be discussed from the perspective of these two environmental constraints. I will show that by using well-established micrometeorological methods and vegetation modelling approaches these lead to relevant constraints that impact and relate to events in human evolution and the emergence of higher civilizations.

\section{Definitions and development of hypotheses}

\subsection{Energetic constraints to human metabolic activity}

One of the fundamental aspects of all life forms is that they require a source of chemical free energy in order to maintain their metabolic reactions and perform work. The dissipation of this free energy is necessary for life forms to maintain their ordered structures, to be able to grow and reproduce (Schrödinger 1944). This, of course, also applies to humans and societies (e.g. Odum 1988 and Smil 1999). A brief survey of the free energy needs to maintain human metabolic activity illustrates the importance of energy: At rest, $100 \mathrm{~W}$ are dissipated by an adult merely due to the basal metabolic rate, of which $30-60 \%$ is due to brain activity, depending on age (e.g. Allman 1999). Light work dissipates $240 \mathrm{~W}$, while heavy work can dissipate up to $1200 \mathrm{~W}$ (Campbell and Norman 1998). Maximum levels of sustained metabolic activity of animals and humans are, however, generally limited to about seven times the metabolic rate at rest (Hammond and Diamond 1997). This empirical observation serves as a physiological constraint on maximum levels of human metabolic activity. Using a typical rate of $100 \mathrm{~W}$ for the metabolic rate at rest, this would set the upper limit of human metabolic activity at $700 \mathrm{~W}$. This is a high consumption rate of free energy compared to the typical fluxes of energy at the Earth's surface. In the global mean, the Earth's surface is heated by about $170 \mathrm{~W} \mathrm{~m}^{-2}$ by the absorption of solar radiation, and cooled by a net emission of terrestrial radiation of about $70 \mathrm{~W} \mathrm{~m}^{-2}$ and turbulent fluxes of about $100 \mathrm{~W} \mathrm{~m}^{-2}$ (Peixoto and Oort 1992). Compared to levels of dissipation in the natural Earth system, a rate of $700 \mathrm{~W}$ is huge e.g. in comparison to an average dissipation rate associated with the atmospheric circulation of about $2 \mathrm{~W} \mathrm{~m}^{-2}$ (Peixoto and Oort 1992). In fact, human brains and human societies are in proportion to their weight - among the most dissipative structures of the Universe (Chaisson 2001).

In order for humans to perform physical work at a rate of a few hundred watts, free energy must be produced by the surrounding biota at a sufficiently high rate before it can be appropriated by humans and dissipated by their metabolisms. This free energy is derived primarily from the terrestrial biosphere, or more 
specifically, from the human appropriation of net primary productivity (HANPP). The appropriation of marine productivity is neglected here, but addressed in the discussion section. In the present day, about $40 \%$ of the global terrestrial productivity is appropriated to human use (Vitousek et al. 1986, 1997; Rojstaczer et al. 2001; Imhoff et al. 2004), although not all of it is used as a source of free energy but also as building materials, firewood etc. The link to metabolic activity and energy consumption is made to terrestrial productivity by considering that one mole of carbon in form of carbohydrate, e.g. glucose, contains about $479 \mathrm{~kJ}$ of free energy. To sustain a metabolic rate of, say, $600 \mathrm{~W}$ for 12 hours per day about $650 \mathrm{gC} \mathrm{d}^{-1}$, or $236 \mathrm{kgC} \mathrm{yr}^{-1}$ of glucose is required. This estimate does not include inefficiencies in the conversions, so that this number states only a minimum appropriation rate. Considering that the highest net primary productivity of natural ecosystems is about $1000 \mathrm{gC} \mathrm{m}^{-2} \mathrm{yr}^{-1}$ and is generally found in the tropics (e.g. Field et al. 1998), it would require a human to appropriate all net primary productivity of an area of $A=236 \mathrm{~m}^{2}$ over the year to sustain such level of metabolic activity. This is again a lower limit, because appropriation of all productivity in a given area would leave no productivity for the vegetative cover to remain productive.

What this simple comparison of energy dissipation and energy fluxes emphasizes is that the need for chemical free energy in maintaining human metabolic activity is considerable, and so is the challenge of disposing the generated heat into the surroundings. The consideration of human metabolic activity in this paper is purely seen from the perspective of environmental constraints. These environmental constraints are a relevant measure for what humans can do (no matter if this is cultural, economic, or any other form of activity) because it also quantifies the maximum possible level of physical work that individual human beings can perform. The ability to perform physical work in turn is a major requirement in order to form and maintain higher civilizations because it is associated with the ability to hunt deer, clear land, plow, maintain and harvest fields, build houses, irrigation systems and roads, etc. Cultural habits, for instance the avoidance of the midday heat in some cultures, can be seen as the consequence to cope with these environmental constraints.

\subsection{Climatic constraints and human metabolic activity}

We can think of the prevailing climatic conditions as imposing two fundamental energetic constraints on maximum possible levels of human metabolic activity (also Schwartzman and Middendorf 2000): First, the climatic conditions affect the productivity of the terrestrial biosphere, which constrains human metabolic activity by supplying the primary source for chemical free energy, in one form or another. Second, the environmental conditions affect the transfer of heat generated by metabolic activity within the human body to the surrounding environment and thereby set limits on human metabolic activity through to the loss of generated heat. Consequently, the maximum in human metabolic activity can, in principle, be viewed as being co-limited by these two fundamental constraints - supply of chemical free energy and ability to loose heat.

This line of reasoning can be quantified by a first-order approximation of the two limiting constraints. The constraint related to the rate at which chemical free energy 
is available, $F_{\text {gain }}$ is assumed to be proportional to the net primary productivity $(N P P)$ of the surrounding vegetative cover:

$$
F_{\text {gain }} \propto N P P
$$

This approximation is a rough, first-order approximation as other factors are important as well, e.g. adjacent marine resources, animal productivity, and presence of large herbivores. These other factors are neglected here for simplicity, i.e. it is assumed that these cannot predict the large-scale patterns as well as NPP (see also discussion section).

The constraint relating to the loss of heat from the body to the environment, $F_{\text {loss }}$, should roughly be proportional to the gradient of the surface temperature of the human body $T_{b}$ and the surrounding, near-surface air temperature $T_{s}$ :

$$
F_{l o s s} \propto\left(T_{b}-T_{s}\right)
$$

Note that this constraint represents the heat loss constraint, which will be dominant in warm environments. It does not capture the requirement to maintain a constant human body temperature in a cold environment, which either forms an energetic cost, or can, for instance, be achieved by clothing, heating by fire, or shelter.

The resulting maximum human metabolic activity $F_{\max }$ is then given by:

$$
F_{\text {max }}=\min \left[F_{\text {gain }}, F_{\text {loss }}\right]
$$

\subsection{Formulation of Hypotheses}

In order to formulate the hypotheses that frame the scope of this paper, we can now ask how these two constraints, $F_{\text {gain }}$ and $F_{\text {loss }}$, vary geographically and how $F_{\text {max }}$ changes as a result of climatic change. The resulting three hypotheses are illustrated schematically in Fig. 1 and explained in the following.

For present-day conditions, these two constraints should vary with latitude as follows: Since $N P P$ is generally higher in the tropics than at the poles, we would expect $F_{\text {gain }}$ to decrease with increasing latitude. I ignore complicating factors at this point, such as the presence of deserts in the subtropics. Assuming that the surface temperature of the human body is approximately constant, but surface temperature decreases with increasing latitude, $F_{\text {loss }}$ should increase with latitude. If both constraints, $F_{\text {gain }}$ and $F_{\text {loss }}$, are roughly of same magnitude at the global scale, then a maximum should exist within the mid-latitudes. Human metabolic activity in tropical regions should be primarily limited by $F_{l o s s}$, and limited by $F_{\text {gain }}$ in polar regions. The same line of reasoning also applies to the altitudinal gradient, for which $F_{\text {loss }}$ would increase with elevation, but $F_{\text {gain }}$ would decrease. This forms my first hypothesis:

Hypothesis 1 (H1) An optimum latitude exists which allows for maximum human metabolic activity.

The past global changes of mean temperature and atmospheric $\mathrm{pCO}_{2}-$ as discussed in the introduction, affect both of these constraints in different ways. In terms of $F_{\text {gain }}$ and $F_{\text {loss }}$, the sensitivity to $\mathrm{pCO}_{2}$ is expressed as follows: On the one hand side, $\mathrm{NPP}$ generally increases with $\mathrm{pCO}_{2}$ and saturates at high $\mathrm{pCO}_{2}$, so that $F_{\text {gain }}$ 
Fig. 1 Simplified diagram illustrating how environmental constraints affect maximum levels of human metabolic activity in the natural environment. Diagram (a) shows a first-order consideration of how the constraints imposed by the supply rate of chemical free energy ("food supply") (dashed line, taken to be proportional to $N P P$ ) and the ability to loose heat (dotted line, roughly proportional to the difference between body and land surface temperature, $T_{b}$ and $T_{s}$ respectively) should vary geographically, and result in a maximum human metabolic activity (solid line). For simplicity, complicating factors such as the presence of deserts in the subtropics are left out here. Diagram (b) shows the expected global sensitivity of the two constraints to atmospheric carbon dioxide $\left(\mathrm{pCO}_{2}\right)$, with $N P P$ and $T_{s}$ both increasing roughly logarithmically with $p \mathrm{CO}_{2}$. Consequently, $T_{b}-T_{s}$ decreases with $\mathrm{pCO}_{2}$. Diagram (c) shows how the geographic variation of constraints displayed in (a) (thin lines) should change for the case of lower atmospheric $\mathrm{pCO}_{2}$ (thick lines). See text for details

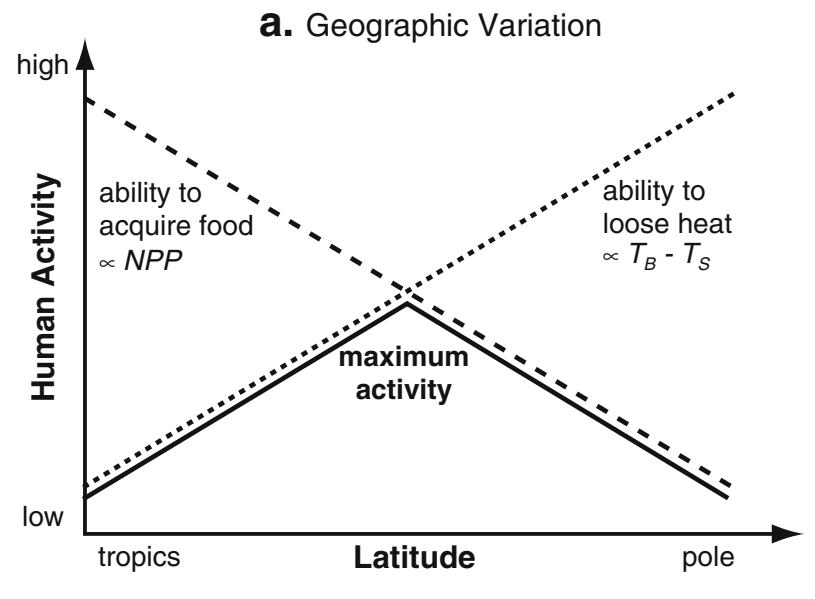

b. Global Change
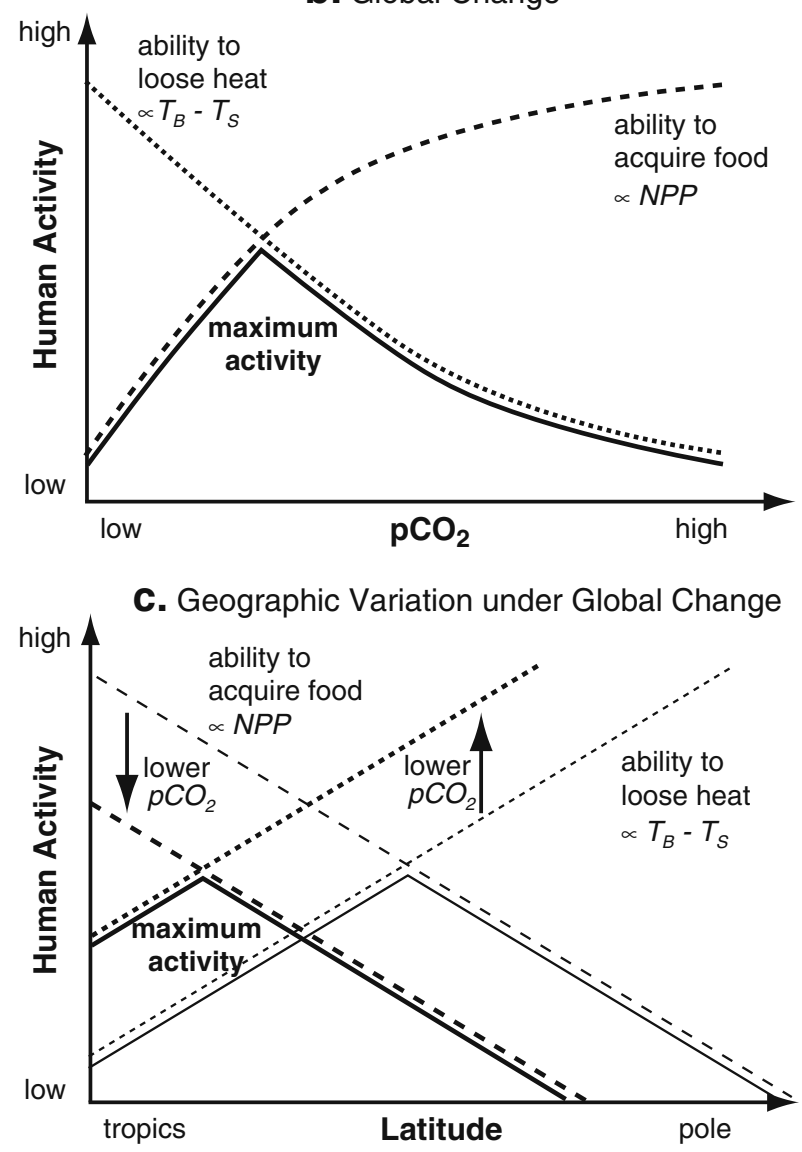
would increase with $\mathrm{pCO}_{2}$. On the other hand, $\mathrm{T}_{s}$ also increases with $p \mathrm{CO}_{2}$, so that the temperature gradient $T_{b}-T_{s}$ decreases. Therefore, $F_{\text {loss }}$ should decrease with $p \mathrm{CO}_{2}$. Hence, we can hypothesize that there is an optimum $\mathrm{pCO}_{2}$ concentration which would allow for maximum human metabolic activity at the planetary scale. Relative to this optimum value of $p \mathrm{CO}_{2}$, lower $\mathrm{pCO}_{2}$ concentrations would lead to human metabolic activity primarily constrained by $F_{\text {gain }}$, while higher $p \mathrm{CO}_{2}$ concentrations would be constrained primarily by $F_{\text {loss }}$. This leads to my second hypothesis:

Hypothesis $2(\mathrm{H} 2)$ An optimum $\mathrm{pCO}_{2}$ concentration exists which allows for maximum human metabolic activity at the global scale.

When we combine both hypotheses, we can further hypothesize that the latitude of maximum human metabolic activity shifts with $\mathrm{pCO}_{2}$. In a colder climate with low $p \mathrm{CO}_{2}$, the $F_{\text {gain }}$ curve is shifted to lower values due to reduced $N P P$, while the $F_{\text {loss }}$ curve shifts to higher values due to the lower $T_{s}$. Both effects shift the maximum of $F_{\max }$ to lower latitudes. Warmer climates with higher $\mathrm{pCO}_{2}$ would lead to the opposite result and shift the optimum latitude further poleward. This leads us to the third hypothesis:

Hypothesis 3 (H3) The optimum latitude that allows for maximum human metabolic activity shifts towards lower latitudes for colder climates, and to higher latitudes for warmer climates.

For completeness I may also formulate the corresponding null hypothesis:

Null Hypothesis Maximum human metabolic activity is independent of the environment.

This could be the result of, for instance, internal (e.g. cultural) constraints that would prevent maximum human metabolic activity to be limited by either of the two environmental constraints. However, key events in human evolution, such as the emergence of agriculture and the locations of higher civilizations, took place in disparate regions under similar climatic conditions during times of climatic change, so that we can easily reject the null hypothesis without much further investigation. Within the scope of this paper I will therefore focus on testing the above three hypotheses.

\section{Methods}

In order to evaluate the three hypotheses, we need to quantify $F_{\text {gain }}$ and $F_{\text {loss }}$ in more detail. While productivity (and therefore $F_{\text {gain }}$ ) is relatively easy to simulate from climatic conditions, an adequate estimation of $F_{\text {loss }}$ is more challenging as it involves several components of the human surface energy balance, in particular radiative exchange and the exchange fluxes of sensible and latent heat at the body's surface. In order to evaluate the heat loss constraint in a relatively reasonable and consistent manner, I use an Earth system model of intermediate complexity, which is able to 
provide a general description of these surface radiative and turbulent fluxes as well as vegetation productivity, and the sensitivity of these fluxes to $\mathrm{pCO}_{2}$.

I use the Planet Simulator (Lunkeit et al. 2004; Fraedrich et al. 2005a, b) as the Earth system model of intermediate complexity. The model consists of a low-resolution atmospheric general circulation model (T21 spectral resolution, corresponding to a spatial resolution of $5.6^{\circ}$ longitude $* 5.6^{\circ}$ latitude, with a 10 layer atmosphere), a simple land surface model, a mixed-layer ocean model, and a dynamic global vegetation model. The model is used to simulate the climatic environment near the surface, in terms of surface temperature $T_{s}$, turbulent fluxes of sensible and latent heat, and the net primary productivity $(N P P)$ of the vegetative cover. These simulated properties form the basis for quantifying $F_{\text {gain }}$ and $F_{\text {loss }}$.

I describe first in Section 3.1 how $N P P$ is calculated in the model, as the major factor contributing to $F_{\text {gain }}$. I base the quantification of $F_{\text {loss }}$ on the existing formulations for turbulent fluxes at the surface and the net radiative exchange, but use these formulations with the temperature $T_{b}$ of the human body surface rather than the temperature of the land surface $T_{s}$. The estimates derived in this way should be viewed as a first-order approximations to illustrate their importance and for evaluating the hypotheses. In Section 3.2 I then describe the setup of the "Control" simulation, of sensitivity simulations to model parameters to evaluate the uncertainty of the simulated constraints, and the setup of sensitivity simulations to $\mathrm{pCO}_{2}$.

\subsection{Calculating environmental constraints to human metabolic activity}

Maximum human metabolic activity is determined as the minimum of a limiting rate by the supply of free energy (food resources) $F_{\text {gain }}$ and by the ability to loose heat to the environment $F_{\text {loss }}$ (Eq. 3), as described above.

\subsubsection{Maximum supply rate of chemical free energy}

The rate $F_{\text {gain }}$ is taken to be proportional to annual mean NPP per unit area:

$$
F_{\text {gain }}=c_{\text {gain }} \cdot N P P
$$

where $c_{\text {gain }}$ is a critical parameter which describes how effective $N P P$ can be converted into chemical free energy that can be utilized by the human metabolism. It is a parameter that depends on many factors such as dietary composition (e.g. grain vs. fruit vs. meat) and it is difficult to estimate. Instead of estimating its value, I take a different approach and use the assumption that the two limiting rates are of roughly equal magnitude at the global scale. Using this as a reference, I then use sensitivity simulations to the value of $c_{\text {gain }}$ to test the implications of this assumption. This approach is described in more detail in Section 3.2.2 below.

The net primary productivity NPP is simulated by SIMBA (e.g. Kleidon 2006), the dynamic global vegetation model that is a part of the climate system model. The carbon uptake by photosynthesis (or, gross primary productivity, GPP) in SIMBA is simulated using a light-limited rate $G P P_{\text {light }}$ and a water-limited rate $G P P_{\text {water }}$, following the approach of Monteith et al. (1989):

$$
G P P=\min \left[G P P_{\text {light }}, G P P_{\text {water }}\right]
$$


The light-limited rate $G P P_{\text {light }}$ is taken to be proportional to the amount of absorbed solar radiation at the surface $F_{s w}$ :

$$
G P P_{\text {light }}=\epsilon_{\text {lue }} \cdot f\left(T_{S}\right) \cdot g\left(p C \mathrm{O}_{2}\right) \cdot f_{\text {leaf }} \cdot F_{S W}
$$

with $\epsilon_{\text {lue }}$ being the light use efficiency, $f\left(T_{s}\right)$ a function which limits $G P P_{\text {light }}$ at low temperatures, $g\left(p \mathrm{CO}_{2}\right)$ the sensitivity to atmospheric concentrations of carbon dioxide (taken to be of logarithmic form), and $f_{\text {leaf }}$ the amount of leaf cover. The water-limited rate $G P P_{\text {water }}$ is taken to be proportional to the rate of evapotranspiration ET:

$$
G P P_{\text {water }}=c_{\mathrm{CO}_{2}} \cdot \frac{p C \mathrm{O}_{2, a}-p \mathrm{CO}_{2, l}}{q_{\text {sat }}\left(T_{s}\right)-q_{a}} \cdot E T
$$

with $c_{\mathrm{CO}_{2}}$ being a conversion factor accounting for the difference in molecular weight of $\mathrm{CO}_{2}$ and $\mathrm{H}_{2} \mathrm{O}$ molecules, $p \mathrm{CO}_{2, a}-p \mathrm{CO}_{2, l}$ and $q_{s a t}\left(T_{s}\right)-q_{a}$ being the gradients of carbon dioxide and water vapor between the leaves' interior and the atmosphere respectively.

NPP is then simply taken to be $50 \%$ of GPP, and is used to evaluate Eq. 4. More details on the dynamic vegetation model are provided in Kleidon (2006).

\subsubsection{Maximum rate of heat loss}

The ability to loose heat $F_{\text {loss }}$ per unit time in a given environment is expressed as a function of heat loss per unit area by sensible and latent heat from the body surface $F_{s h, b}$ and $F_{l h, b}$ respectively, and the net radiative loss $F_{r a d, b}$ :

$$
F_{\text {loss }}=A_{b} \cdot\left(F_{\text {sh }, b}+F_{l h, b}+F_{\text {rad }, b}\right)
$$

where $A_{b}$ is the surface area of the body (taken to be $A_{b}=2 \mathrm{~m}^{2}$, Campbell and Norman 1998). The turbulent fluxes are calculated from the simulated values for land surfaces of the climate model, $F_{s h, s}$ and $F_{l h, s}$. These are then converted to the corresponding values for the heat loss from the body surface by:

$$
\begin{gathered}
F_{s h, b}=F_{s h, s} \cdot \frac{T_{b}-T_{2 m}}{T_{s}-T_{2 m}} \\
F_{l h, b}=F_{l h, s} \cdot \frac{q_{b}-q_{2 m}}{q_{s}-q_{2 m}}
\end{gathered}
$$

where $T_{b}=307 \mathrm{~K}$ is taken as the skin temperature of the body (Campbell and Norman 1998), $q_{b}$ is the specific humidity at the body surface, and $T_{2 m}$ and $q_{2 m}$ are the air temperature and specific humidity at a reference height of $2 \mathrm{~m}$. It is assumed that $q_{b}=q_{s a t}\left(T_{b}\right)$ in order to calculate the maximum rate of heat loss by sweating. The assumption of a saturated (and naked) body surface is acceptable here since it is used to obtain only an upper estimate for potential heat loss, not its actual value. In addition, the value of $F_{l h, b}$ is limited to an empirical maximum sweat rate of $F_{l h, b, \max }=760 \mathrm{~W}$ (Campbell and Norman 1998).

The net radiative loss $F_{r a d, b}$ is

$$
F_{r a d, b}=F_{s w, b}-\sigma\left(T_{b}^{4}-T_{2 m}^{4}\right)
$$


with $\sigma$ being the Stefan-Boltzmann constant. For simplicity, it is assumed that absorption of solar radiation $F_{s w, b}=0 \mathrm{~W} \mathrm{~m}^{-2}$, which should yield an estimate of maximum heat loss which is biased towards higher values.

Note that by using the simulated value of $F_{l h, s}$ of the land surface, the prevailing water availability for evapotranspiration by the vegetative cover enters the estimate for $F_{\text {loss }}$. That is, in regions where no water is available (e.g. deserts), a powerful way to loose heat is not available $\left(F_{l h, s} \approx 0\right)$, so that $F_{l o s s}$ is composed effectively only of $F_{s h, b}$ and $F_{r a d, b}$. While this is a reasonable consequence of this approach, this should nevertheless kept in mind for the later analysis and interpretation of the results.

\subsection{Simulation setup}

\subsubsection{The "Control" setup}

As a reference point, a "Control" simulation is conducted with present-day forcing conditions with $\mathrm{pCO}_{2}=360 \mathrm{ppm}$. This simulation includes a mixed-layer ocean model which simulates sea surface temperatures. Equations 4-11 are included into the model as an additional diagnostic, that is, the equations do not affect the simulated climate. Also enabled in the simulation is the diurnal cycle and $F_{\text {loss }}$ is computed only over periods of daylight (i.e. periods for which $F_{s w}>0$ ).

The first 100 years of the simulation are used to determine the oceanic heat transport for the mixed layer ocean model. The heat transport in the ocean model was determined by relaxing simulated sea-surface temperatures to the present-day climatology. An additional 50 years are simulated with prescribed oceanic heat transport to yield the "Control" climate. As shown in Fig. 2, the "Control" simulation captures the general, large-scale variations of annual precipitation, temperature, and vegetation productivity reasonably well, despite some regional shortcomings (e.g. dry spot in central Amazonia, Australia too dry, and a weak Indian monsoon). The last 10 years are used to calculate the mean climatology of the "Control".

\subsubsection{Determination of $c_{\text {gain }}$}

The parameter $c_{\text {gain }}$ plays an important role in determining the availability of free energy $F_{\text {gain }}$ (cf. Eq. 4). I use the assumption that the global mean value of $F_{\text {gain }}$ is equal to $F_{\text {loss }}$ for the present-day, so that $c_{\text {gain }}=\overline{F_{\text {loss }}} / \overline{N P P}$ where the overbar denotes global averaging over land over the last 10 years of the "Control". I choose this approach because I have much higher confidence in the adequate treatment of heat transfer fluxes in the model that are used to determine $F_{\text {loss }}$. The heat flux formulations are (a) commonly used and (b) lead to realistic distribution of the sensible and latent heat flux for the land surface. Therefore, $F_{\text {loss }}$ should yield an adequate, first order approximation. The value of $c_{\text {gain }}$ derived in this way then serves as a reference point.

The sensitivity of the model results to the particular value of $c_{\text {gain }}$ is then estimated by a sensitivity analysis in which the value of $c_{\text {gain }}$ is decreased and increased by a factor of 10 . I refer to these setups as " $0.1 \mathrm{x}$ " and " $10 \mathrm{x}$ " respectively. These simulations do not require a complete re-run of the model simulation, but are simply applied to the monthly mean output. This sensitivity is also performed for the sensitivity simulations to $\mathrm{pCO}_{2}$ (see next subsection). 
Fig. 2 Annual mean temperature (top), precipitation (center), and net primary productivity (bottom) of the "Control" simulation
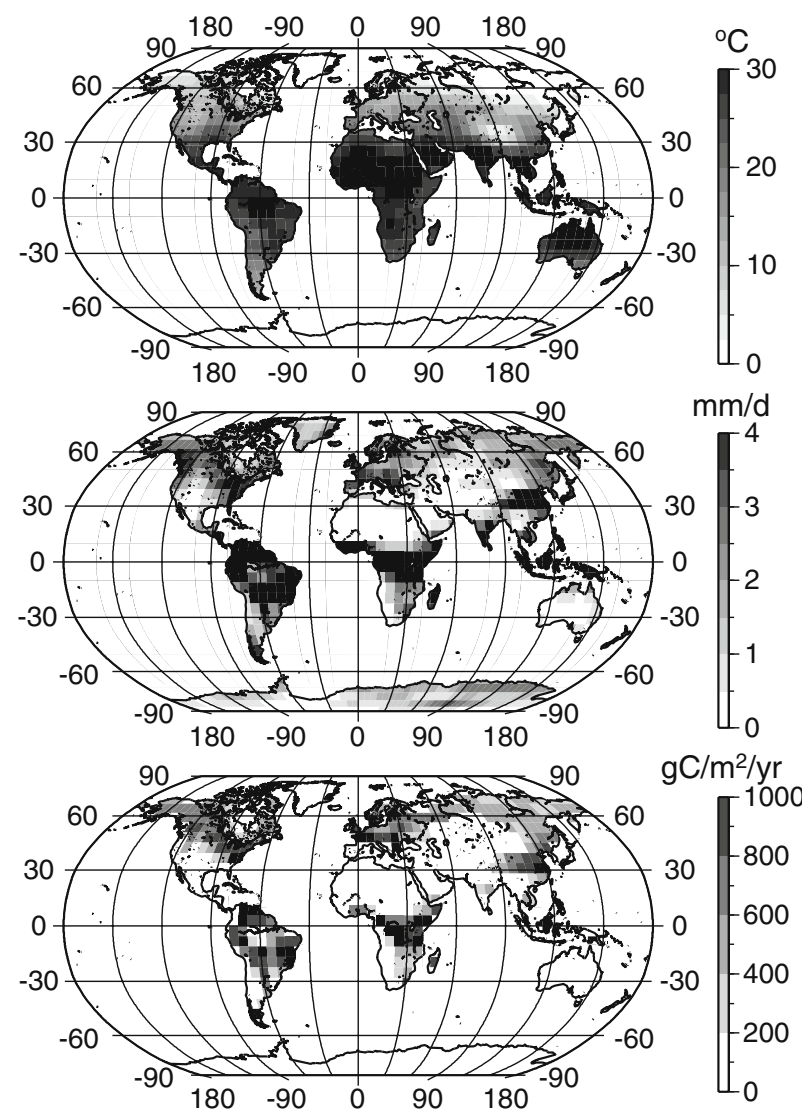

\subsubsection{Sensitivity to $\mathrm{pCO}_{2}$}

The sensitivity of $F_{\max }$ to global climatic change is simulated by conducting a range of simulations at different values of $\mathrm{pCO}_{2}$. I use values of $p \mathrm{CO}_{2}=100,200,280$, $360,540,720,1000,2000,3000,5000,10000 \mathrm{ppm}$. For each value of $p C \mathrm{O}_{2}$, the model is run for 50 years with prescribed oceanic heat transport values derived from the "Control" simulation. The last 10 years are used to calculate the mean climate for the evaluation. The model shows a reasonable sensitivity in the global land mean values of $T_{s}$ and $N P P$, as shown in Fig. 3. Note that the simulated sensitivities shown in Fig. 3 also include many climate system feedbacks, such as differences in cloud cover and availability in soil water, which affect both sensitivities.

The temperature sensitivity shown in Fig. 3 is consistent with the general logarithmic relationship to $\mathrm{pCO}_{2}$ which is found in sensitivity simulations of more complex climate system models (e.g. the NCAR climate system model, Oglesby and Saltzman 1992; Kothavala et al. 1999). The resulting spatial patterns of annual mean temperature difference in these simulations is also largely consistent with those e.g. of the IPCC (2001), showing an elevated sensitivity in higher latitudes (not shown). The almost doubling in NPP with doubled $\mathrm{pCO}_{2}$ is consistent with the sensitivity of more complex global dynamic vegetation models (Cramer et al. 2001). 
Fig. 3 Simulated sensitivity of near surface temperature averaged over land (solid line) and net primary productivity (NPP, dotted line) to the atmospheric concentration of carbon dioxide $\mathrm{pCO}_{2}$

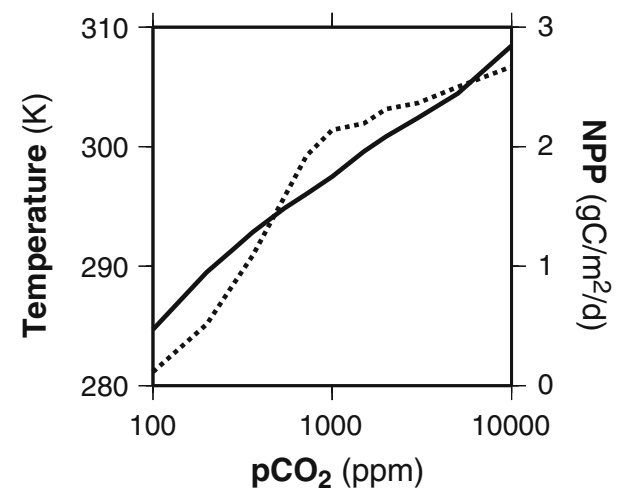

The extreme values of $100 \mathrm{ppm}$ and $10000 \mathrm{ppm}$ are included in the sensitivity simulations mainly to extend the overall sensitivity to two orders of magnitude in $\mathrm{pCO}_{2}$ (esp. for evaluation of hypothesis $\mathrm{H} 2$ ). However, the extremes push the limits of validity of some of the model parameterizations. This applies to the parameterization of photosynthesis, which is likely to yield biases towards overestimating photosynthetic rate for $\mathrm{pCO}_{2}$ levels close or below the light compensation point and at high $\mathrm{pCO}_{2}$ where photosynthetic rate saturates (e.g. Larcher 1995). Both of these shortcomings are due to the simple logarithmic relationship included in the term $g\left(p \mathrm{CO}_{2}\right)$ in Eq. 6. However, the extreme values are only included in the analysis of the global mean sensitivity to demonstrate the existence of a maximum, so that the overall results and conclusions should not be affected much by the associated biases in the model parameterizations at the extreme $\mathrm{pCO}_{2}$ concentrations.

Note that other important factors of climatic change, such as the presence or absence of ice sheets, changes in orbital parameters, and changes in other greenhouse gases are not considered here.

\section{Results}

\subsection{Evaluating H1}

The simulated geographic distributions of the two constraints $F_{\text {gain }}$ and $F_{\text {loss }}$ as well as the resulting maximum human metabolic activity $F_{\max }$ are shown in Fig. 4 for the "Control" setup of present-day conditions.

The geographic distribution of $F_{\text {gain }}$ mirrors the distribution of NPP shown in Fig. 2, except for being scaled by the constant $c_{\text {gain }}=185.206 \mathrm{~W} \mathrm{gC}^{-1} \mathrm{~m}^{-2} \mathrm{~d}^{-1}$. It shows maximum values in the highly productive regions of the tropics, Eastern Asia, Western Europe, and Eastern North America. The minimum values of $F_{\text {gain }}$ are found in the subtropical latitudes in central America, North- and Southwestern Africa, Australia and inner Asia where the lack of water availability highly constrains $N P P$, an effect that was excluded in Fig. 1 . The patterns are driven primarily by water availability in the tropics, and therefore show corresponding biases in the simulated climate. For instance, a local minimum in central Amazonia which is driven by low 
Fig. 4 Supply rate of chemical free energy from appropriation of terrestrial productivity, $F_{\text {gain }}$ (top), maximum heat loss $F_{\text {loss }}$ (center), and maximum human metabolic activity $F_{\max }$ (bottom) of the "Control" simulation

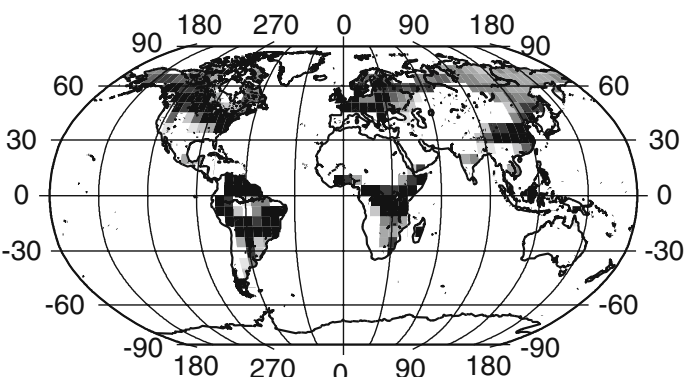

W 1200 800 $-400$
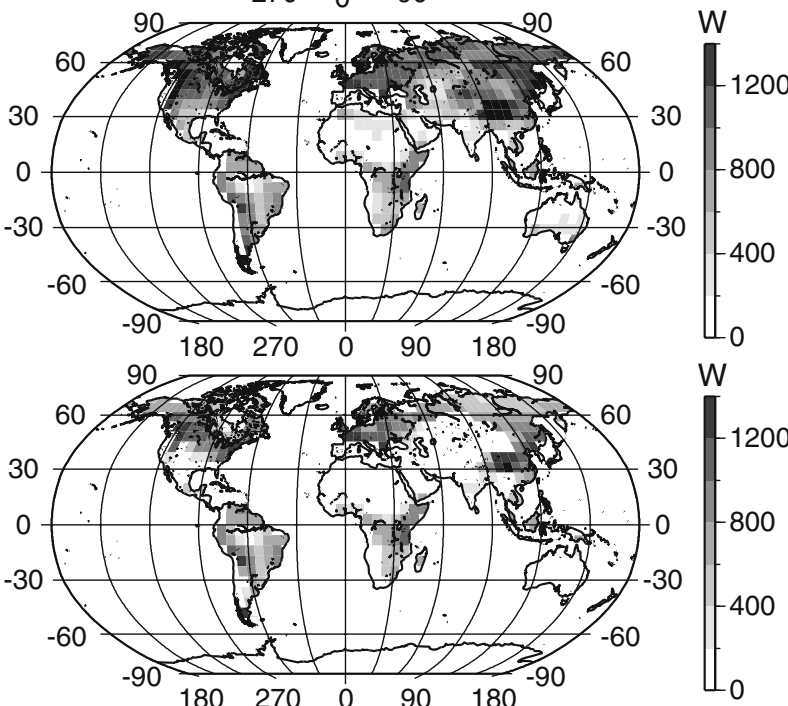

precipitation (cf. Fig. 2). In the high latitudes, $F_{\text {gain }}$ reflects limitations imposed by cold temperatures and the length of the growing season.

The ability to loose heat $F_{\text {loss }}$ generally increases towards the poles, as hypothesized. $F_{\text {loss }}$ also increases with higher altitude in the tropics to the extent to which this is resolved in the model. This can be seen in the Andes region in South America and the Tibetan plateau. The low values found in the desert regions result primarily from the low rates of evapotranspiration, which reduce the latent heat flux and thereby $F_{\text {loss }}$ as described in Section 3.1. It is important to recognize that the simulated peak values of $F_{\text {loss }}$ of $\sim 1000 \mathrm{~W}$ are of the same magnitude as the maximum rates of dissipation by human metabolic activity. This means that heat loss from the human body to the natural environment is indeed an important and relevant constraint on human metabolic activity in the simulated climate.

The resulting maximum human metabolic activity $F_{\max }$ then shows peaks in the mid-latitude humid regions of Europe, China, and Eastern North America, and, to a lesser extent, East Africa and the Andes region in South America. Minimum values for $F_{\max }$ are located in the desert regions of the subtropics and in high latitudes. The maximum levels are shaped by the trade-offs associated with the two constraints, and this trade-off is well reflected in the zonal averages shown in Fig. 5. The zonal averages of $F_{\max }, F_{\text {gain }}$ and $F_{\text {loss }}$ show that maximum levels of human metabolic 
Fig. 5 Sensitivity of maximum levels of human metabolic activity to the assumed value of $c_{\text {gain }}$, represented by zonal annual means of $F_{\text {gain }}$ (dotted line), $F_{\text {loss }}$ (dashed line), and $F_{\text {max }}$ (solid line) for the "Control" setup (top), the " $0.1 \mathrm{x}$ " setup (middle) and the "10x" setup (bottom)

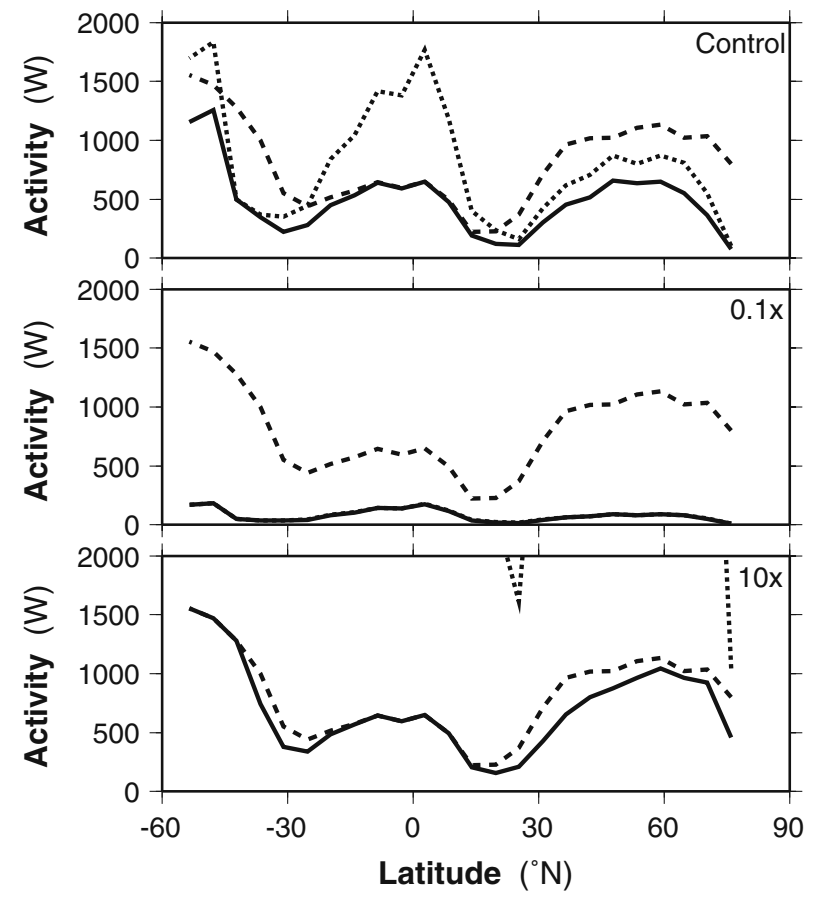

activity in the tropics is primarily limited by $F_{l o s s}$, while in the high latitudes it is limited by $F_{\text {gain }}$. In the temperate regions, human metabolic activity results from a seasonal covariance among the constraints (not shown). This results in two maxima in latitude, with the maximum in temperate regions marginally exceeding the tropical maximum in the zonal mean.

The sensitivity of $F_{\text {gain }}, F_{\text {loss }}$, and $F_{\text {max }}$ to the choice of $c_{\text {gain }}$ is also shown in Fig. 5. A reduced value of $c_{\text {gain }}$ in the " $0.1 \mathrm{x}$ " simulation leads to a lower supply rate of chemical free energy, so that the maximum human metabolic activity traces very closely $F_{\text {gain }}$ as the main limitation, and therefore follows the zonal distribution of $N P P$. The resulting maximum level of activity is substantially reduced and hardly exceeds the basal metabolic rate of $100 \mathrm{~W}$. An increased value of $c_{\text {gain }}$ in the simulation "10x" substantially reduces the limitation by the supply rate of chemical free energy, so that the maximum human metabolic activity follows more closely $F_{\text {loss }}$. As a result, the maximum human metabolic activity is primarily constrained by the ability to loose heat. This does not affect $F_{\max }$ in the tropics, but in the temperate regions, $F_{\max }$ is noticeably increased compared to the "Control". The reasonability of the actual value of $c_{\text {gain }}$ used in the "Control" is discussed in detail in Section 5.1.4 below.

\subsection{Evaluating $\mathrm{H} 2$}

The sensitivity of the global land averages of $F_{\text {gain }}, F_{\text {loss }}$, and $F_{\text {max }}$ to $p \mathrm{CO}_{2}$ is shown in Fig. 6. As a result of increased $\mathrm{NPP}$ with $\mathrm{pCO}_{2}, \mathrm{~F}_{\text {gain }}$ increases with $\mathrm{pCO}_{2} . \mathrm{F}_{\text {loss }}$ 
Fig. 6 Sensitivity of land averaged $F_{\text {gain }}$ (dotted line), $F_{\text {loss }}$ (dashed line), and $F_{\text {max }}$ (solid line) to $\mathrm{pCO}_{2}$ for the standard setup

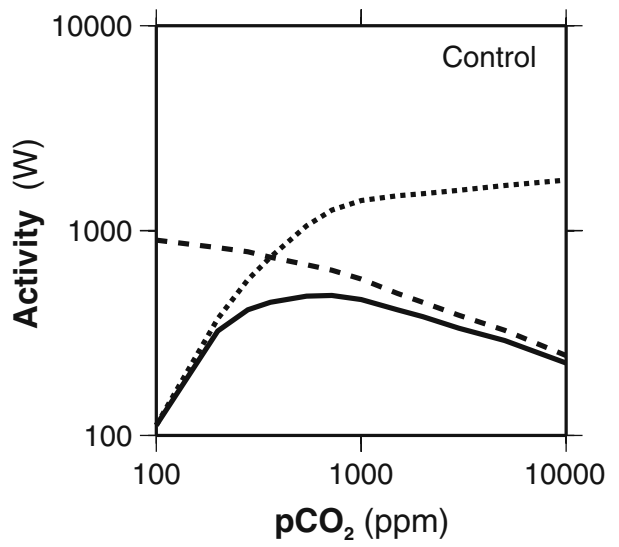

decreases with $\mathrm{pCO}_{2}$ due to the increase in global land temperature. Consequently, $F_{\text {max }}$ shows a clear global maximum value at about $p \mathrm{CO}_{2}=700 \mathrm{ppm}$, but it is important to note that the actual location of the maximum is highly sensitive to the assumed value of $c_{\text {gain }}$, as shown in the following.

Figure 7 shows the sensitivity of $F_{\text {gain }}$ and $F_{\text {loss }}$ to the assumed value of $c_{\text {gain }}$. In the " $0.1 \mathrm{x}$ " setup, the maximum shifts to a higher values of $\mathrm{pCO}_{2}$, and the actual overall $F_{\text {max }}$ is reduced. This is consistent with $F_{\text {gain }}$ being the dominant limitation in the " $0.1 \mathrm{x}$ " setup. With increasing values of $\mathrm{pCO}_{2}, \mathrm{~F}_{\text {gain }}$ becomes less limiting, and the limiting impact of $F_{\text {loss }}$ takes place at a higher value of $\mathrm{pCO}_{2}$. In the "10x" setup, the maximum shifts to lower values of $p \mathrm{CO}_{2}$, and the resulting $F_{\max }$ is higher than in the "Control". This, again, is consistent with the " $10 x$ " setup in which $F_{l o s s}$ is more
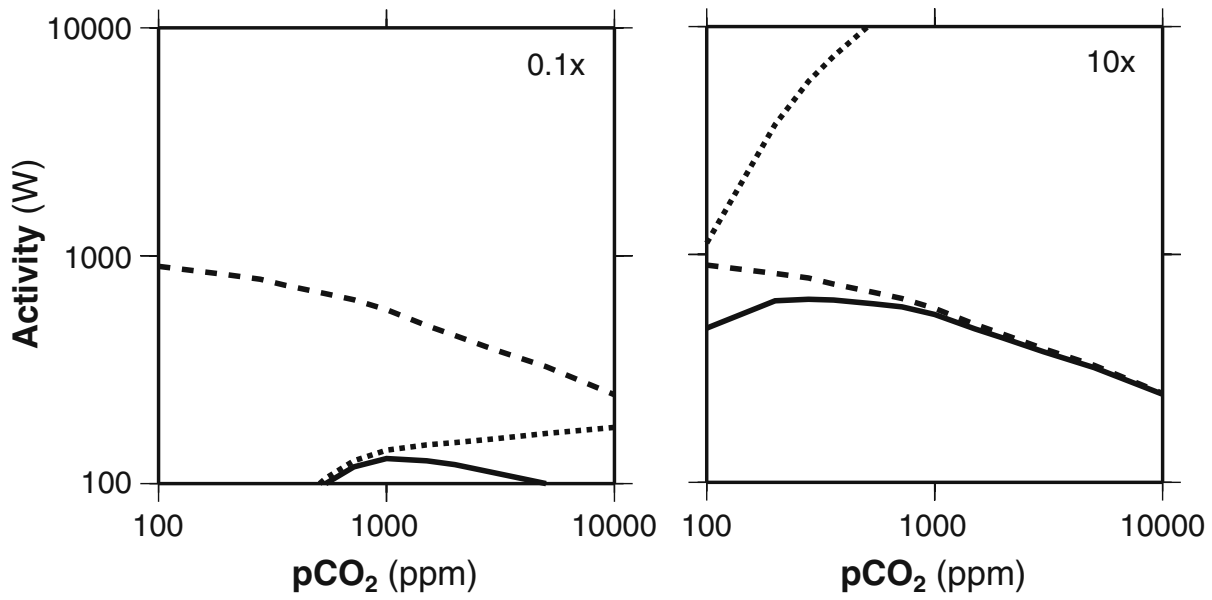

Fig. 7 Same as Fig. 6, but for setups "0.1x" (left) and "10x" (right) 
limiting, and $F_{\text {gain }}$ plays a less important role. Consequently, $F_{\text {gain }}$ becomes limiting at lower values of $\mathrm{pCO}_{2}$, shifting the location of the maximum also to lower $\mathrm{pCO}_{2}$.

As in the evaluation of $\mathrm{H} 1$, the " $0.1 \mathrm{x}$ " setup leads to maximum levels of $F_{\text {max }}$ that barely exceed the basal metabolic rate. The "10x" setup is similar to the "Control" setup, but with $F_{\text {loss }}$ being the dominant constraint.

\subsection{Evaluating $\mathrm{H} 3$}

To examine H3, I have averaged $F_{\max }$ over tropical regions (taken to be represented by $10^{\circ} \mathrm{S}-10^{\circ} \mathrm{N}$ ) and over the northern hemisphere extratropics ("temperate regions", averaged over $40^{\circ} \mathrm{N}-60^{\circ} \mathrm{N}$ ). The averages for these two regions are shown in Fig. 8. The averaging clearly shows that $F_{\text {max }}$ is greater in the tropics for cold, low $p \mathrm{CO}_{2}$ climates, with a peak around $p \mathrm{CO}_{2}=200 \mathrm{ppm}$. The maximum human metabolic activity in temperate regions surpasses the one in tropical regions between $280 \mathrm{ppm}$ and $360 \mathrm{ppm}$, and peaks around $\mathrm{pCO}_{2}=720 \mathrm{ppm}$.

The results of the " $0.1 x$ " and " $10 x$ " sensitivity setups are shown in Fig. 9. In the " $0.1 \mathrm{x}$ " setup, $F_{\text {gain }}$ is substantially more limiting and $F_{\text {max }}$ traces $F_{\text {gain }}$. Consequently, $F_{\text {max }}$ in the tropics is greater than in the temperate regions for all $p \mathrm{CO}_{2}$ levels investigated. The magnitudes of $F_{\max }$ are substantially less than in the "Control". In the " $10 x$ " setup, the limitations by $F_{\text {gain }}$ are much reduced. Consequently, $F_{\max }$ is primarily limited by $F_{\text {loss }}$. This can also be seen in Fig. 8 in that the sensitivity to $p \mathrm{CO}_{2}$ is essentially identical to the "Control" for high $\mathrm{pCO}_{2}$. In this setup, $F_{\max }$ in the temperate regions exceeds the one in the tropical regions for all simulated values of $\mathrm{pCO}_{2}$.

These results demonstrate that the shift in regions of maximum human metabolic activity (as formulated in H3) occurs if colimitation exists, that is, that $F_{\text {max }}$ results from the associated trade-offs between $F_{\text {gain }}$ and $F_{\text {loss }}$ with the balance shifting across different geographic regions.

Fig. 8 Sensitivity of $F_{\max }$ for tropical $\left(10^{\circ} \mathrm{S}-10^{\circ} \mathrm{N}\right.$, solid line) and extratropical $\left(40^{\circ} \mathrm{N}-60^{\circ} \mathrm{N}\right.$, dotted line $)$ regions to atmospheric $\mathrm{pCO}_{2}$

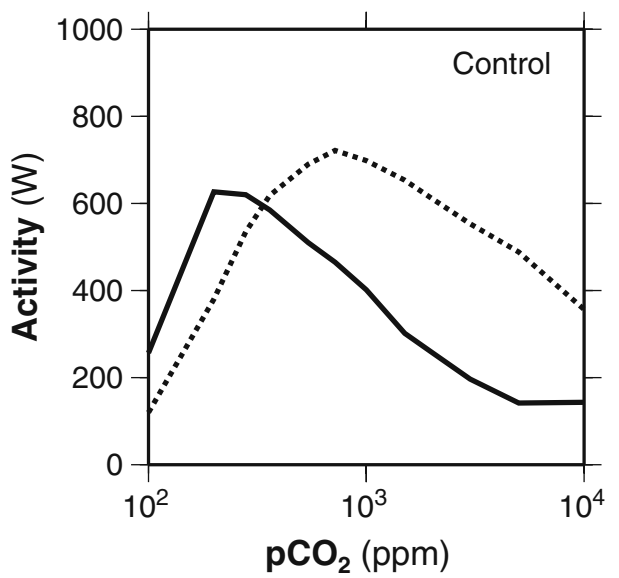



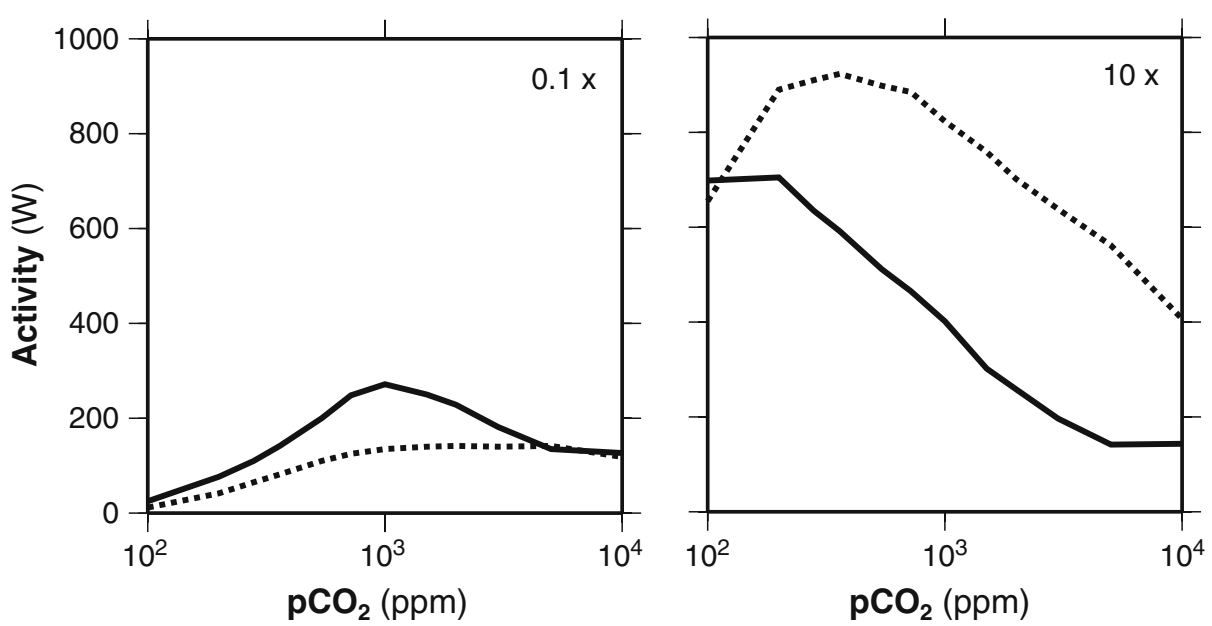

Fig. 9 Same as Fig. 8, but for setups "0.1x" (left) and "10x" (right)

\section{Discussion}

I first provide a qualitative account of the inherent limitations of the methodology used here, discuss reasonable values of $c_{\text {gain }}$, and then discuss how the results relate to human evolutionary history and climatic change.

\subsection{Limitations}

Naturally, the approach taken here is highly simplistic, as well as its implementation. However, the basic approach, using climatic constraints on overall human metabolic activity, is clearly applicable to humans as it is to any other living organism. The quantification of constraints circumvents the problems associated with environmental determinism: Constraints merely quantify what individuals cannot do in a given environment (in terms of levels of metabolic activity), but do not determine what individuals actually will do. Since the quantification of the constraints plays a central role in this approach, the following discussion of the limitations of this study focuses strongly on whether the two constraints considered here have been adequately formulated.

\subsubsection{Modelling of the supply rate of free energy}

The first constraint, the supply rate of chemical free energy, has been treated simply as being proportional to terrestrial productivity of the vegetative cover. This simplification neglects that some sources of free energy have higher free-energy content than others (e.g. fats versus sugars). The accessibility and density of free energy sources are also not taken into account. For instance, large herbivores can graze grasslands, but not forests. Also, the human appropriation of the chemical free energy provided by the terrestrial productivity reduces the share available for biomass increase or consumption by other organisms. Such interactions are not included in the simple approach used here. Nevertheless, the simple, assumed proportionality of supply rate 
of chemical free energy to NPP should capture the broad geographic distribution of food supply to first order.

The supply rate of chemical free energy by the adjacent marine biosphere (e.g. along coasts, lakes, and rivers) or the use of water for irrigation for vegetation productivity (e.g. in the Nile river valley) are also not taken into account. These factors are clearly important at the local to regional scale. However, the focus here was on capturing the patterns of human metabolic activity on the larger, continental scale. Using a simulation model of higher resolution and an extension in the parameterization for the supply rate of chemical free energy to include adjacent aquatic resources would potentially allow for the inclusion of these factors in an extension of this study.

Also neglected in the approach are potential feedbacks from different intensities of human appropriation of vegetation productivity to vegetation growth and climate. Such feedbacks would become important as the intensity of appropriation takes place at a sufficiently large scale. This is clearly the case today, where about $40 \%$ of the global land area are put into direct use by humans (Vitousek et al. 1997). Such feedbacks could, in principle, be included into the model. An example of how this could be implemented is given in Kleidon (2006), where the concept of human appropriation of vegetation productivity was used to estimate the climate sensitivity to land cover change.

Other important factors that affect the supply rate of chemical free energy include the amount of physical work required to clear and maintain the land for agriculture, and the availability of fertilizers. At the onset of agriculture, this strongly relates to the availability of surrounding wildlife for domestication, as pointed out by Diamond (1997). For instance, oxes can be used to plow fields and can "take over" some of the physical work required in maintaining agriculture. In more recent times these factors strongly relate to the utilization of fossil sources of chemical free energy: Fossil fuels allow for the clearing and maintenance of agricultural land by fuel-driven machinery, for the distribution of free energy in the form of trading food, and for the production of fertilizers, which are energetically expensive to produce. These factors seem to be clearly of importance for adequately modeling present-day supply rate of chemical free energy, but would require considerable effort to be included in the study here (but see Section 5.2.2 below).

\subsubsection{Modelling of heat loss}

The simulation of heat loss from the body surface seems to be implemented in a fairly robust way, because it is based on established micrometeorological theory. Consequently, biases in the parameterization may account for relatively small deviations, perhaps in the order of tens of $\mathrm{W} \mathrm{m}^{-2}$. But the overall magnitude of the simulated fluxes should nevertheless be within the range that is relevant as a constraint on human metabolic activity. The exclusion of absorption of shortwave radiation makes the estimated values of heat loss conservative in that the constraints on overall heat loss is likely to be underestimated.

On the other hand, other forms of cooling, particularly by breathing, have not been taken into account. This may account for as much as $10 \%$ of the metabolic heat generation (e.g. Campbell and Norman 1998), although its importance decreases in warmer and more humid environments (which is where $F_{\text {loss }}$ is the dominant constraint). 
Another factor not considered here are local- to regional scale sources of water, e.g. sources of ground water, rivers, and lakes, that would enable humans to maintain higher evaporation rates and thereby increase their heat loss. This factor is relevant in regions in which water is limiting the rate of evapotranspiration, such as subtropical arid regions in general, and the Nile river valley in particular.

An important factor which allows for enhanced heat loss in an industrial world is the availability of air-conditioned housing, which allows for the control of the temperature in the immediate surroundings, and, consequently, the amount of heat loss. This constitutes a "decoupling" from the natural climatic environment, where the implementation of the approach taken here is no longer valid. It is, however, important to realize that this decoupling is made possible by the vast consumption of fossil fuels (air conditioning units run on electricity).

\subsubsection{Other constraints}

This study used merely two constraints to quantify maximum levels of human metabolic activity. Surely, there are many other potential constraints of physical, biological, and cultural nature that may limit human metabolic activity. One obvious additional physical constraint is that the body temperature needs to be maintained within a narrow range, which may require the use of energy for thermoregulation. This energy would then not be available for other human metabolic activity, so that the overall level of human metabolic activity would be reduced. However, this reduction can be offset by insulation through skin or clothing. The inclusion of this constraint would require more relevant information about the specific values associated with actual heat loss, e.g. the heat conductance of skin. This could, in principle, be addressed by extending this study.

However, it is important to recognize that these additional constraints would impact the results mainly with regards to the actual levels of human metabolic activity. The maximum levels of metabolic activity obtained here should still hold as upper physical limits so that the conclusions we can draw from the results should be unaffected by these limitations.

\subsubsection{Actual value of $c_{\text {gain }}$}

The results depend quite strongly on the assumed value of $c_{\text {gain }}$, in terms of (i) the optimum latitude at which maximum value of $F_{\max }$ is found for the present day; (ii) the optimum value of $\mathrm{pCO}_{2}$; and (iii) the shift in optimum latitude associated with different values of $\mathrm{pCO}_{2}$.

In the " $0.1 \mathrm{x}$ " setup, the supply of food resources becomes so limiting that activity levels peak at $200 \mathrm{~W}$ (Fig. 5), which is barely twice the metabolic activity at rest. Under such constraints, the emergence of agriculture and higher civilizations would be impossible, because higher levels of human metabolic activity would be needed to plow fields and build houses. The sensitivity to $\mathrm{pCO}_{2}$ for this setup would be such that the metabolic activity at rest could not be sustained at the prevailing $p \mathrm{CO}_{2}$ levels of about 200 ppm during ice ages (Fig. 7). It would therefore seem that a value of $c_{\text {gain }}$ that is lower by an order of magnitude than the value used for the "Control" simulation leads to unrealistic results.

In the " $10 \mathrm{x}$ " setup, human metabolic activity is predominantly constrained by heat loss $F_{\text {loss }}$. This leads to a zonal variation of maximum human metabolic activity 
being almost identical to the heat loss (Fig. 5). Furthermore, it leads to activity levels that are noticeably higher in the extratropics than in the tropics for almost all levels of simulated $\mathrm{pCO}_{2}$ (Fig. 8). However, the maximum human metabolic activity at glacial $\mathrm{pCO}_{2}$ is inconsistent with studies that show that seed production by crops was considerably reduced at these levels of $p \mathrm{CO}_{2}$ (Sage 1995). This maximum would also be inconsistent with the observation that agriculture evolved independently in different regions of similar climate after glacial termination (Diamond 1997). It would therefore seem that the actual value used for $c_{\text {gain }}$ in the "Control" simulation is reasonable, although it may be higher by a factor of 2 or 4 , but not 10 . This would further imply that the assumption that both constraints are roughly of the same magnitude is reasonable. The remaining uncertainty in $c_{\text {gain }}$ would have relatively little consequence for the overall magnitude of $F_{\text {max }}$, but it would affect the latitudinal distribution of $F_{\max }$ (Fig. 5), the location of the optimal $\mathrm{pCO}_{2}$ concentration shown in Fig. 6, and affects the shift in optimum latitude as shown in Fig. 8.

I will assume that the simulations with the "Control" value of $c_{\text {gain }}$ are sufficiently reasonable for the following interpretation of the results.

\subsection{Human metabolic activity and climate change}

\subsubsection{Interpreting human evolution in a changing climate}

In the introduction I described the general trend over the last 50 million years towards colder climates to motivate this investigation between climatic conditions and levels of human metabolic activity. Two significant shifts to colder climates were emphasized, occurring (i) at the end of the Eocene with the onset of Antarctic glaciation, and (ii) at the end of the Miocene with the onset of Northern hemisphere glaciation and glacial cycles. Both shifts coincided roughly with important evolutionary events on land, with (i) the emergence of large mammals and (ii) the emergence of Homo erectus with a trend to larger brain sizes in relation to body size.

Commonly, the emergence of Homo erectus at the beginning of the Pleistocene is attributed to the reduced forest habitat as the terrestrial climate became colder and drier, forcing Homo erectus into open grasslands. Such a colder climate, possibly caused by lower levels of $p \mathrm{CO}_{2}$, would likely result in a less productive environment, providing less food resources to humans. Hypothesis $\mathrm{H} 2$ and the related results shown here would lead to an alternative interpretation: It would seem that the main limitation of human metabolic activity of a warmer Miocene climate would possibly not be the supply rate of chemical free energy, but the ability to loose heat. The cooler environment of the Pliocene (and even more so in the Pleistocene) would provide an environment that would allow for more heat loss (i.e. increase $F_{\text {loss }}$ ), thus enabling humans to perform more physical work. This could, for instance, result in more extensive hunting which would in turn increase the supply and quality of the supply of chemical free energy. Considering that brain activity contributes about $33-66 \%$ of the metabolic activity at rest, the higher levels of human metabolic activity and the increase in the quantity and quality of the supply of chemical free energy would then allow for the evolution towards larger brains (as documented e.g. in Vrba 1995). Furthermore, the results presented here quantitatively confirm the hypothesis of Schwartzman and Middendorf (2000)) that warm climates impose important constraints on the evolution of large brains in relation to body size. 
Fig. 10 Global land mean surface temperature $T_{S}$ versus maximum heat loss $F_{\text {loss }}$ derived from the $\mathrm{pCO}_{2}$ sensitivity simulations

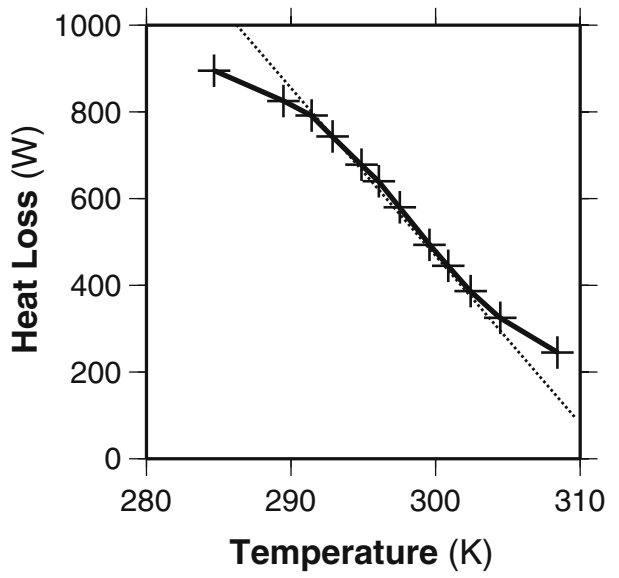

The direct connection between maximum possible heat loss and global mean temperature is more apparent when the simulated value of heat loss $F_{\text {loss }}$ is plotted directly against the global land mean of surface temperature $T_{s}$, rather than $\mathrm{pCO}_{2}$. This is shown in Fig. 10. What Fig. 10 shows is a clear and almost linear decrease in maximum heat loss with global land temperature, with a rate of decrease of about $d F_{\text {loss }} / d T_{s}=-32.4 \mathrm{~W} / \mathrm{K}$. This decrease should also hold for other causes of warming (e.g. changes in atmospheric methane), as $F_{\text {loss }}$ relates to $T_{s}$, and only indirectly to $p \mathrm{CO}_{2}$.

While the estimates for heat loss were derived for humans, with respect to body temperature, surface area, and maximum sweat rate, the general, constraining nature of heat loss would seem to be applicable also to other animals, although with other parameter values. This then would lead to a consistent relationship between the emergence and rapid evolution of large mammals and the reconstructed global cooling by as much as $10^{\circ} \mathrm{C}$ at the end of the Eocene. Using the slope of $d F_{\text {loss }} / d T_{s}=$ $-32.4 \mathrm{~W} / \mathrm{K}$, such a cooling would potentially allow for metabolic activity levels to increase by more than $320 \mathrm{~W}$. This would be a considerable increase in possible levels of metabolic activity, and could have led to the emergence of large mammals with enhanced metabolic activity. Further evaluation of temperature constraints on animals on an evolutionary time scale would seem to be of great interest, particularly considering that Zotin (1984) reports a trend over the last 500 million years towards animal species that have increased metabolic rates at rest in relation to their body mass. A logical question to ask about this trend would be whether the emergence times of species with higher metabolic rates could be predicted from changing environmental constraints.

The shift in latitude at which maximum human metabolic activity takes placeas formulated in hypothesis $\mathrm{H} 3$ - would seem relevant for the interpretation of human evolution during glacial cycles. While much of human evolution took place during glacial times in tropical Africa, the emergence of higher civilizations occurred during the present interglacial period in the extratropics and at higher altitudes. This seeming contradiction can be understood here by the sensitivity of the latitude (or altitude) at which maximum human metabolic activity takes place. As a consequence of the trade-off between $F_{\text {gain }}$ and $F_{\text {loss }}$, warmer periods result in the maximum being 
located in the extratropics, while it is located in the tropics during colder periods (Fig. 8).

Not investigated here are the impacts of longer-term climate variability during the Holocene, such as the medieval warm period and the northward expansion of the Norse, the little ice age, or e.g. the drought in the 8th and 9th century that is associated with the collapse of the Mayan civilization (Haug et al. 2003). These would clearly affect the two constraints and the geographic pattern of maximum human metabolic activity. These periods would possibly provide further test cases for the approach developed here, but would require climate model simulations that are capable of resolving regional climatic details and these modes of climate variability.

\subsubsection{Human metabolic activity and global warming}

The approach developed here can serve as a quantitative measure for how "habitable" climatic conditions are for humans in terms of their metabolic activity in their natural environment. Such a quantitative measure of "human habitability" is important as we try to better understand the implications of anthropogenic climatic change. Human metabolic activity would provide a better measure than e.g. temperature, because temperature has contrasting effects on human metabolic activity. When temperatures are cold, they can limit human metabolic activity, either indirectly by impacting NPP or directly through e.g. energy expenditures related to thermoregulation. When environmental temperatures are too warm, they can limit human metabolic activity by reducing the magnitude of heat loss as shown in Fig. 10. The quantification of human metabolic activity as done here leads to a more straightforward interpretation: Climates resulting in higher values of $F_{\max }$ are always "better" in that climate is less constraining to human metabolic activity.

From a theoretical viewpoint, this definition of human habitability is consistent with the general characterization of dissipative Earth system processes by their associated rates of entropy production (e.g. Kleidon and Lorenz 2005). Since human metabolic activity is associated with the dissipation of chemical free energy into heat at about the temperature of the human body, temperature variations play essentially no role in the rate of entropy production associated with human metabolic activity. Consequently, entropy production would be directly proportional to $F_{\max }$. In this sense, the evaluation of climate in terms of $F_{\max }$ would put it on the same thermodynamic basis as purely physical processes, e.g. turbulence in the atmosphere (Ozawa et al. 2003), or terrestrial vegetation (Kleidon 2002, 2004).

Maps of human metabolic activity shown in Fig. 4 also demonstrates the practical value of maximum human metabolic activity as a measure of habitability. Given the coarse model resolution, simulated high levels of human metabolic activity match reasonably well the location where higher civilization developed, namely in Europe, China, and at high altitudes in the Andes. As outlined by hypothesis H1, these are not regions of high $N P P$, but result from the trade-off between $F_{\text {gain }}$ and $F_{\text {loss }}$ in intermediate regions for the present-day climate.

When we evaluate the climate sensitivity to elevated $\mathrm{pCO}_{2}$ in the context of anthropogenic emissions of carbon dioxide ("global warming") in terms of this measure of human habitability, we need to first distinguish between (a) the direct effects of fossil fuel use on human metabolic activity and (b) the climatic effects of elevated $\mathrm{pCO}_{2}$ on the habitability of the natural environment. 
(a) Direct effects of fossil fuels. The vast use of fossil fuels provides humans with substantially more chemical free energy and results in enhanced work performed by humans and enhanced dissipation. This enhanced dissipation due to fossil fuels affects human metabolic activity in two different ways: First, it increases the supply rate of chemical free energy, e.g. by the production of synthetic fertilizers, for machinery in agriculture, and for the distribution of food. Secondly, it creates more habitable local environments, e.g. by air conditioning. Both factors increase $F_{\max }$ due to effects that are mainly independent of the climatic conditions. But we should keep in mind that the use of fossil fuels as a source of chemical free energy is unsustainable and will eventually decline. This would ultimately result in a reduction in $F_{\max }$ unless other sources of chemical free energy can replace fossil fuels.

(b) Climatic impacts of elevated $\mathrm{pCO}_{2}$. The sensitivity of $\mathrm{F}_{\max }$ to $\mathrm{pCO}_{2}$ (Fig. 6) can directly address the effect of global warming on human habitability of the climatic environment. These results show that the enhancement of NPP as a consequence of raised levels of $\mathrm{pCO}_{2}$ would seem to have beneficial effects on humans in terms of increasing $F_{\text {gain }}$. Yet at least of equal importance is the degradation of the climatic environment in terms of reduced values of $F_{\text {loss }}$ with increasing $\mathrm{pCO}_{2}$. This is an aspect that is generally not considered when discussing the consequences of global warming on humans. This trade-off between $F_{\text {gain }}$ and $F_{\text {loss }}$ led to an optimum value for $\mathrm{pCO}_{2}$, although this value is sensitive to $c_{\text {gain }}$. The increased efficiency of food production (as discussed above under (a)) would result in a higher value of $c_{\text {gain }}$, that is, a higher value of $F_{\text {gain }}$ is achieved under the same climatic conditions. This, in turn, would shift the optimum value of $\mathrm{pCO}_{2}$ towards lower concentrations associated with cooler climates.

Taken together, this suggests the conclusion that even though the direct effects of energy consumption related to fossil fuels increase $F_{\max }$, the human habitability of the natural environment would seem to decrease with global warming. This would, however, require a more quantitative evaluation to support this tentative conclusion.

\section{Summary and conclusion}

In this paper, I viewed maximum levels of human metabolic activity as being constrained primarily by two environmental factors and argue that these are related to overall human evolution and the geographic locations of where higher civilizations emerged. The two environmental factors that were investigated are the supply rate of chemical free energy by human appropriation of terrestrial productivity and the ability to loose heat to the environment. While the first factor has led to insights regarding the emergence of agriculture after the last ice age (Sage 1995), the second factor has not received much attention, although Schwartzman and Middendorf (2000) linked the evolution of "big brains" to the general cooling trend over the last 50 million years.

Based on these two constraints, I developed three hypotheses to characterize maximum levels of possible human metabolic activity allowed for by the climatic environment in relation to (i) geographic variations in climate for the present-day, (ii) global-scale variations in $\mathrm{pCO}_{2}$ and global mean temperature and (iii) how the 
geographic variation shifts for different levels of $\mathrm{pCO}_{2}$. In order to evaluate these hypotheses quantitatively, I used explicit formulations of the constraints and incorporated them into a climate system model. The three hypotheses were supported by these simulations under the reasonable assumption that both limitations are roughly of equal importance. Despite the highly simplistic nature of the approach, it leads to reasonable predictions that seem to be relevant to understand human evolution in relation to climate. Its application to present-day conditions is able to reproduce the geographic locations where higher civilizations were formed. Applied to the climate sensitivity to $\mathrm{pCO}_{2}$, this perspective points out that colder climates are more favorable to humans and animals that have high metabolic activities in that a colder climate enables them to loose more heat. And last, the shift in latitude at which maximum human metabolic activity occurs with glacial-interglacial variations can explain the seeming contradiction that most of evolutionary human history took place in tropical Africa during glacial periods, while human civilizations formed in the extratropics (or at higher altitudes) during interglacials, but not in the tropics.

Admittedly, the approach taken here is highly simplistic, leaves out many details, and can be improved substantially in the future. It provides a starting point to quantifying the habitability of climatic conditions for humans. This in turn would allow us to shift the focus of climate sensitivity from indirect and ambiguous measures such as surface temperature to a human-centric measure. This measure of "habitability" appears to be more meaningful basis to investigate the linkages between climate and climatic change with human evolution than the focus on purely abiotic factors such as continental dryness or global mean temperature.

The importance of the heat loss constraint that emerged from this study is likely to have wider ranging implications. First it would seem to be a relevant constraint for the past evolution of mammals in general (and other animals, such as birds, reptiles etc.), not just humans. Secondly, it would also seem to have direct implications for the impacts of global warming due to burning of fossil fuels. A warmer world would allow for less heat loss, and this would have direct effects on metabolic activity, not just of humans in their natural environment, but also for mammals in general. While the effects of elevated $\mathrm{pCO}_{2}$ on plant growth is generally emphasized (which relaxes the constraint of the supply rate of chemical free energy), heat loss is likely to become increasingly constraining. It would therefore seem that changes in this constraint result in important detrimental consequences of global warming on the Earth's biosphere and humans in their natural environment.

Acknowledgements I thank Charles Christian and David Schwartzman for stimulating and critical discussions about the ideas that resulted in this paper and three reviewer (one of them being David, another Rik Leemans) for their comments. This work was partially supported by the National Science Foundation through grant ATM 513506.

Open Access This article is distributed under the terms of the Creative Commons Attribution Noncommercial License which permits any noncommercial use, distribution, and reproduction in any medium, provided the original author(s) and source are credited.

\section{References}

Allman JM (1999) Evolving brains. Scientific American Library, New York

Campbell GS, Norman JM (1998) An introduction to environmental biophysics, 2nd edn. Springer Publishers, New York, NY 
Cerling TE, Harris JM, MacFadden BJ, Leakey MG, Quade J, Eisenmann V, Ehleringer JR (1997) Global vegetation change through the Miocene/Pliocene boundary. Nature 389:153-158

Chaisson EJ (2001) Cosmic evolution: rise of complexity in nature. Harvard University Press, Cambridge, MA

Cramer W, Bondeau A, Woodward FI, Prentice IC, Betts RA, Brovkin V, Cox PM, Fischer V, Foley JA, Friend AD, Kucharik C, Lomas MR, Ramankutty N, Sitch S, Smith B, White A, YoungMolling C (2001) Global response of terrestrial ecosystem structure and function to CO2 and climate change: results from six dynamic global vegetation models. Glob Chang Biol 7:357-373

Crowley TJ, North GR (1991) Paleoclimatolgy. Oxford University Press, New York

Diamond J (1997) Guns, germs, and steel: the fates of human societies. Norton and Company, Inc., New York, NY

Field CB, Behrenfeld MJ, Randerson JT, Falkowski P (1998) Primary production of the biosphere: integrating terrestrial and oceanic components. Science 281:237-240

Fraedrich K, Jansen H, Kirk E, Luksch U, Lunkeit F (2005a) The planet simulator: towards a user friendly model. Z Meteorol 14:299-304

Fraedrich K, Jansen H, Kirk E, Lunkeit F (2005b) The planet simulator: green planet and desert world. Z Meteorol 14:305-314

Hammond KA, Diamond J (1997) Maximal sustained energy budgets in humans and animals. Nature 386:457-462

Haug GA, Guenther D, Peterson LC, Sigman DM, Hughen KA, Aeschlimann B (2003) Climate and the collapse of Maya civilization. Science 299:1731-1735

Huntington E (1915) Civilization and climate. Yale University Press, New Haven, Conn

Imhoff ML, Bounoua L, Ricketts T, Loucks C, Harriss R, Lawrence WT (2004) Global patterns in human consumption of net primary production'. Nature 429:870-873

IPCC (2001) Climate change 2001: the scientific basis. Contribution of working group I to the third assessment report of the intergovernmental panel on climate change. Cambridge University Press, Cambridge, United Kingdom and New York, NY, USA

Kleidon A (2002) Testing the effect of life on earth's functioning: how Gaian is the earth system? Clim Change 66:271-319

Kleidon A (2004) Beyond Gaia: thermodynamics of life and earth system functioning. Clim Change 66:271-319

Kleidon A (2006) The climate sensitivity to human appropriation of vegetation productivity and its thermodynamic characterization. Glob Planet Change 54:109-127

Kleidon A, Lorenz RD (eds) (2005) Non-equilibrium thermodynamics and the production of entropy: life, earth, and beyond. Springer Verlag, Heidelberg, Germany

Kothavala Z, Oglesby RJ, Saltzman B (1999) Sensitivity of equilibrium surface temperature of CCM3 to systematic changes in atmospheric CO2. Geophys Res Lett 26:209-212

Lamb HH (1982) Climate, history and the modern world. Routledge, London, New York

Larcher W (1995) Plant physiological ecology, 3rd edn. Springer Publishers, New York, NY

Lear CH, Elderfield H, Wilson PA (2000) Cenozoic deep-sea temperatures and global ice volumes from $\mathrm{Mg} / \mathrm{Ca}$ in benthic foraminiferal calcite. Science 287:269-272

Long SP, Ainsworth EA, Leakey ADB, Noesberger J, Ort DR (2006) Food for thought: lower-thanexpected crop yield stimulation with rising CO2 concentrations. Science 312:1918-1921

Lunkeit F, Fraedrich K, Jansen H, Kirk E, Kleidon A, Luksch U (2004) Planet simulator reference manual. Available at http://puma.dkrz.de/plasim

Monteith JL, Huda AKS, Midya D (1989) RESCAP: a resource capture model for sorghum and pearl millet. In: Virmani SM, Tandon HLS, Alagarswamy G (eds) Modelling the growth and development of sorghum and pearl millet, Vol 12. ICRISAT Research Bulletin, Patancheru, India, pp 30-34

Odum HT (1988) Self-organization, transformity, and information. Science 242:1132-1139

Oglesby RJ, Saltzman B (1992) Equilibrium climate statistics of a general circulation model as a function of atmospheric carbon dioxide. I - Geographic distributions of primary variables. J Clim 5:66-92

Ozawa H, Ohmura A, Lorenz RD, Pujol T (2003) The second law of thermodynamics and the global climate system - a review of the maximum entropy production principle. Rev Geophys 41:1018

Pearson PN, Palmer MR (2000) Atmospheric carbon dioxide concentrations over the past 60 million years. Nature 406:695-699

Peixoto JP, Oort AH (1992) Physics of climate. American Institute of Physics, New York, NY

Petit JR, Jouzel J, Raynaud D, Barkov NI, Barnola J-M, Basile I, Bender M, Chappellaz J, Davis M, Delaygue G, Kotlyakov VM, Legrand M, Lipenkov VY, Lorius C, Pepin L, Ritz C, Saltzman E, 
Stievenard M (1999) Climate and atmospheric history of the past 420,000 years from the Vostok ice core, Antarctica. Nature 399:429-439

Ritter C (1852) Einleitung zur Allgemeinen vergleichenden Geographie und Abhandlungen zur Begründung einer mehr wissenschaftlichen Behandlung der Erdkunde. G. Reimer, Berlin

Rojstaczer S, Sterling SM, Moore NJ (2001) Human appropriation of photosynthesis products. Science 294:2549-2552

Sage RF (1995) Was low atmospheric CO2 during the Pleistocene a limiting factor for the origin of agriculture? Glob Chang Biol 1:93-106

Schrödinger E (1944) What is life? The physical aspect of the living cell. Cambridge University Press, Cambridge, UK

Schwartzman DW, Middendorf G (2000) Biospheric cooling and the emergence of intelligence. In: Lemarchand G, Meech K (eds) A new era in bioastronomy, Vol 213. ASP Conference Series, pp 425-429

Smil V (1999) Energies - an illustrated guide to the biosphere and civilization. MIT Press, Cambridge, Massachusetts

Vitousek PM, Ehrlich PR, Ehrlich AH, Matson PA (1986) Human appropriation of the products of photosynthesis. Bioscience 36:368-373

Vitousek PM, Mooney HA, Lubchenco J, Melillo JM (1997) Human domination of earth's ecosystems. Science 277:494-499

Vrba ES (1995) The fossil record of African Antelopes (Mammalia, Bovidae) in relation to human evolution and paleoclimate. In: Vrba ES, Denton GH, Partridge TC, Burckle LH (eds) Paleoclimate and evolution, with emphasis on human origins. Yale University Press, New Haven, CT, and London, UK, pp 385-424

Vrba ES, Denton GH, Partridge TC, Burckle LH (eds) (1995) Paleoclimate and evolution, with emphasis on human origins. Yale University Press, New Haven, CT, and London, UK

Zachos J, Pagani M, Sloan L, Thomas E, Billups K (2001) Trends, rhythms, and aberrations in global climate $65 \mathrm{Ma}$ to present. Science 292:686-693

Zotin AI (1984) Bioenergetic trends of evolutionary progress of organisms. In: Lamprecht I, Zotin AI (eds) Thermodynamics and regulation of biological processes. de Gruyter, Berlin, New York, pp 451-458 